\title{
What the Hell Am I Doing Here? A Look at a Series of Geriatric Centers, Profile of the Institutionalized Persons and Reasons for Admission
}

Pascual López, José A. ${ }^{1}$; Rodriguez Lavado, Paula ${ }^{2}$; García Jimenez, Catalina ${ }^{2}$; Fernandez Valero, Francisco J. ${ }^{2}$; Aracil Fernández, Javier ${ }^{1}$; Martinez López, Pedro M. ${ }^{1}$; Gómez Hortelano, Arantxa ${ }^{1}$; Ros Marín, María ${ }^{1}$; Martínez Delgado, Concepción ${ }^{1}$; Perez Carrillo, Alfredo ${ }^{1}$ and López Giraldo, Daniel

1. Family Physician, Primary Care Health Center, Calasparra 30420, Murcia, Spain

2. Family Medicine Resident, Primary Care Health Center, Calasparra 30420, Murcia, Spain

\begin{abstract}
The main objective of this study was always to know the profile of the institutionalized people in our environment, to know their reality: age, age of admission, level of dependency and evolution during their stay, years of stay, number of children, reason for admission. We use data from more than 600 patients from different residences of different backgrounds: public and private, lay and religious, rural and urban. We performed a descriptive study expressing the results in percentages with standard deviation and later evaluated the statistical significance of the differences using the student's t-test for the quantitative and Chi-square variables to compare qualitative variables. The results of the study are numerous and of diverse nature, because of their extension, from the general profile of the resident, to the important gender differences, attributed in principle to the different roles of each gender in the studied generations. There are also differences depending on the funding, the reason for admission or the environment. This is at the end only the beginning of a large comparative study with non-institutionalized population, in order to compare this population.
\end{abstract}

Key words: Geriatric assessment, aged, housing of the elderly, patient admission, healthcare financing, environment, sex.

\section{Introduction}

The aging process generates important changes in the lifestyle of the population with significant repercussions on the volume and distribution of the social burden of disease. The UN (United Nations) states that it is a sequential, cumulative and irreversible phenomenon, which deteriorates the organism progressively until it is unable to cope with circumstances and conditions in the environment [1].

This descriptive study shows data referring to the profile of the institutionalized patient in geriatric residences to elucidate conclusions about their status in the same and their evolution according to the

Corresponding author: Pascual López, José A., family physician, honorary professor, research fields: diabetes, geriatric health. previous environment (urban or rural), sex and age [2].

This study shows that the rural area implies a greater dependence of the resident for psychiatric problems, especially in women [3]. On the other hand, in the urban area, urologic pathology and psychosocial problems are more frequent.

Ultimately, we could advance by studying the causative factors of pathology according to the environment where each resident has developed [4].

\section{Material and Methods}

Scope: five geriatric residences located in our medium of different profile (urban/rural, public/private). We studied all residents by collecting data on gender, AA (age of admission), CA (current age), AS (average length of stay), marital status, children, RA (reason for admission), funding, DE 
(degree of dependency at entry) and DC (current degree of dependency), associated limiting pathologies: dementia, Alzheimer's disease, psychiatric disorders, cerebrovascular disease (CVA), diaper use and psychoactive drugs. We used the statistical program G-Stat with Excel as database. We evaluated the statistical significance of the differences using Student's t-test for quantitative and Chi-square variables to compare qualitative variables.

\section{Results}

Gender: women $63 \%$, men $37 \%$. Age on Admission: $78.1 \% \pm 0.45$ years. Current Age: $82.07 \pm 0.4$ years. Average stay: $4 \pm 0.18$ years. Civil status: married $14.64 \%$, single $25.82 \%$, divorced $8.29 \%$, widowed $51.25 \%, 54 \%$ of residents have 1 or no children. Reason for admission: $24.66 \%$ entered by physical dependence; $26.59 \%$, for neuropsychiatric reasons; $48.75 \%$, due to social problems (Fig. 1). Financing AA: Public regime (RPub) $77 \pm 0.67$, private regime (RPriv) $79.15 \pm 0.6(p=0.018)$. CA: There are no significant differences. AS: RPub $4.57 \pm 0.31$, RPriv $3.56 \pm 0.21(p=0.007)$ DE: (RPub) $48.52 \pm 2.07$, (RPriv) $62.99 \pm 2.05$ ( $p=0.001)$. DC: (RPub) $39.34 \pm$ 2.08, (RPriv) $54.14 \pm 2.22(p=0.002)$. Dementia: (RPub) 30.25\%，(RPriv) 25.63\% $(p=0.0022)$. Alzheimer's disease: (RPub) 15.61\%, (RPriv) 7.32\% ( $p<0.0001$ ). CVA: (RPub) 9.06\%, (RPriv) 3.66\% ( $p$ $<0.0001)$. Psychiatric disorder: there are no significant differences. Associated Neuropsychiatric Pathology AA: D (Dementia) $78.98 \pm 0.55, \mathrm{ND}$ (non-dementia) $77.02 \pm 0.75(p=0.03)$. P (Psychiatric disorder) 75.66 \pm 0.85 , NP (no psychiatric disorder) $79.39 \pm 0.52(p=$ 0.0008). CA: (D) $83.09 \pm 0.47$, (ND) $80.76 \pm 0.69$ ( $p$ $=0.004)$. (P) $79.27 \pm 0.73$, (NP) $83.51 \pm 0.47$ ( $p=$ $0.0005)$. There are no significant differences regarding the age of admission, current age or AS in
Alzheimer's and Stroke. DE: (D) $47.64 \pm 1.86$, (ND) $66.64 \pm 2.23(p<0.0001)$. Alzheimer (A) $41.97 \pm 2.72$, no Alzheimer (NA) $60.21 \pm 1.7(p=0.0002)$. CVA $42.87 \pm 4.02$, in no CVA $48.83 \pm 1.69(p=0.0022)$ DC (D) $36.57 \pm 1.89$, (ND) $60.25 \pm 2.32(p=0.0009)$. (A) $27.09 \pm 2.49,(\mathrm{NA}) 52.95 \pm 1.78(\mathrm{p}=0.0009)$. CVA $34.58 \pm 3.46$, no CVA $48.83 \pm 1.69(p=0.0022)$. There are no significant differences in DE or DC in psychiatric disorder (Fig. 2). Neuropsychiatric diseases: $55.88 \%$ presented some type of pathological cognitive deterioration, of which $42 \%$ corresponded to Alzheimer's disease $(22.93 \%$ of residents). The $12.72 \%$ have suffered a stroke; $34.1 \%$ some type of psychiatric disorder. Level of dependency (DE/DC): independent $13.49 / 10.2 \%$, mild dependence $10 / 9.6 \%$, moderate $27.75 / 20.23 \%$, severe $24.08 / 25.43 \%$, total $24.6 / 34.49 \%$. The average Barthel income is $56,027 \pm$ 1.49 ; the current, $47.02 \pm 1.55$. The $72.64 \%$ use diapers and $76.49 \%$ use psychotropic drugs (Fig. 3). Areas: Age of admission: Rural (R) $76.15 \pm 0.81$ Urban (U) $79.18 \pm 0.53 p=0.0013$. Current age: (R) $80.62 \pm 0.81$ (U) $82.85 \pm 0.43 P=0.008$. Average length of stay: (R) $4.48 \pm 0.29$ (U) $3.81 \pm 0.24 p=$ 0.089. Children: (R) $1.18 \pm 0.09$ (U) $1.62 \pm 0.084 p=$ 0.0009. Reason for admission: Social (R) $38.2 \%(\mathrm{U})$ $54.5 \%$ Neuropsychiatry $\quad(\mathrm{R}) \quad 46.6 \%$ (U) $15 \%$ Physicaldependence (R) 15\% (U) 30\% $p<0.0001$. Dependence: Barthel income (R) $51.75 \pm 2.48$ (U) $58.35 \pm 1.85 p=0.034$. Severe-total dependence on income (R) $54.64 \%$ (U) $43.75 \% p=0.0176$. Barthel current: (R) $40.56 \pm 2.55$ (U) $50.53 \pm 1.93$ $\mathrm{p}=(\mathrm{R}) 44.8 \%(\mathrm{U}) 61.9 \% p=0.0002$ Psychiatric Disorders: (R) 69.4\% (U) 53.27\% p = (R) $19.67(\mathrm{U})$ $41.96 p<0.0001$ Urinary incontinence (R) $86.34 \%$ (U) $65.18 p<0.0001 \quad$ Alzheimer's, stroke and psychoactive drugs use: There are no significant differences. 

Institutionalized Persons and Reasons for Admission

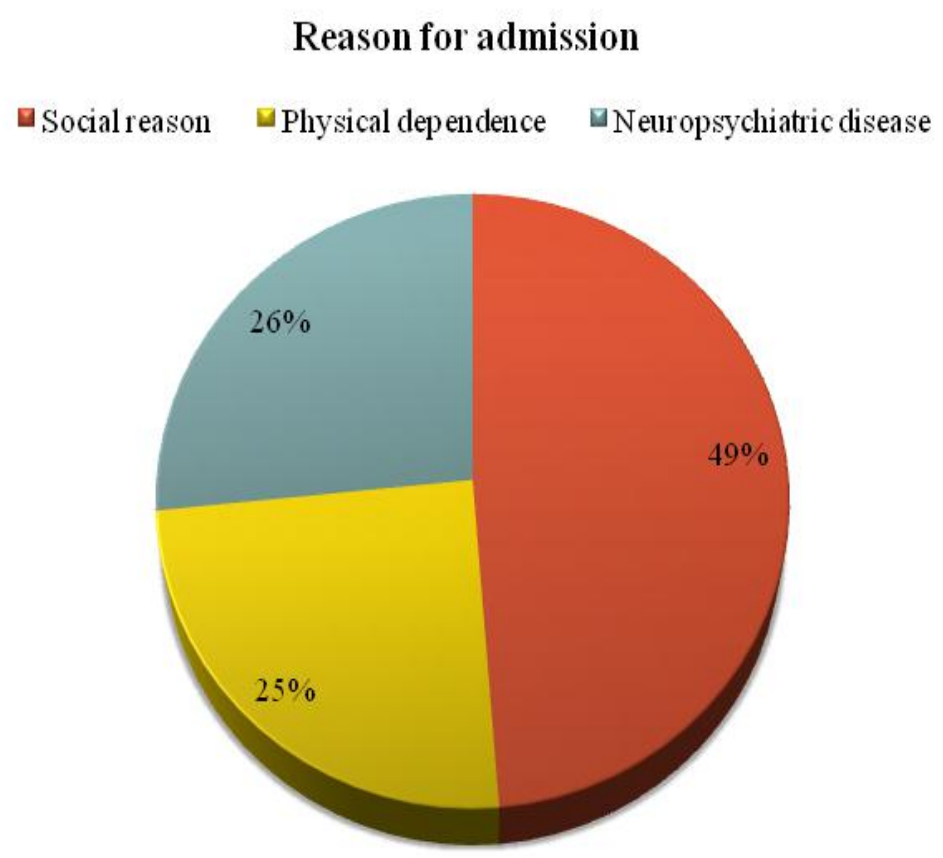

Fig. 1 Reason for admission.

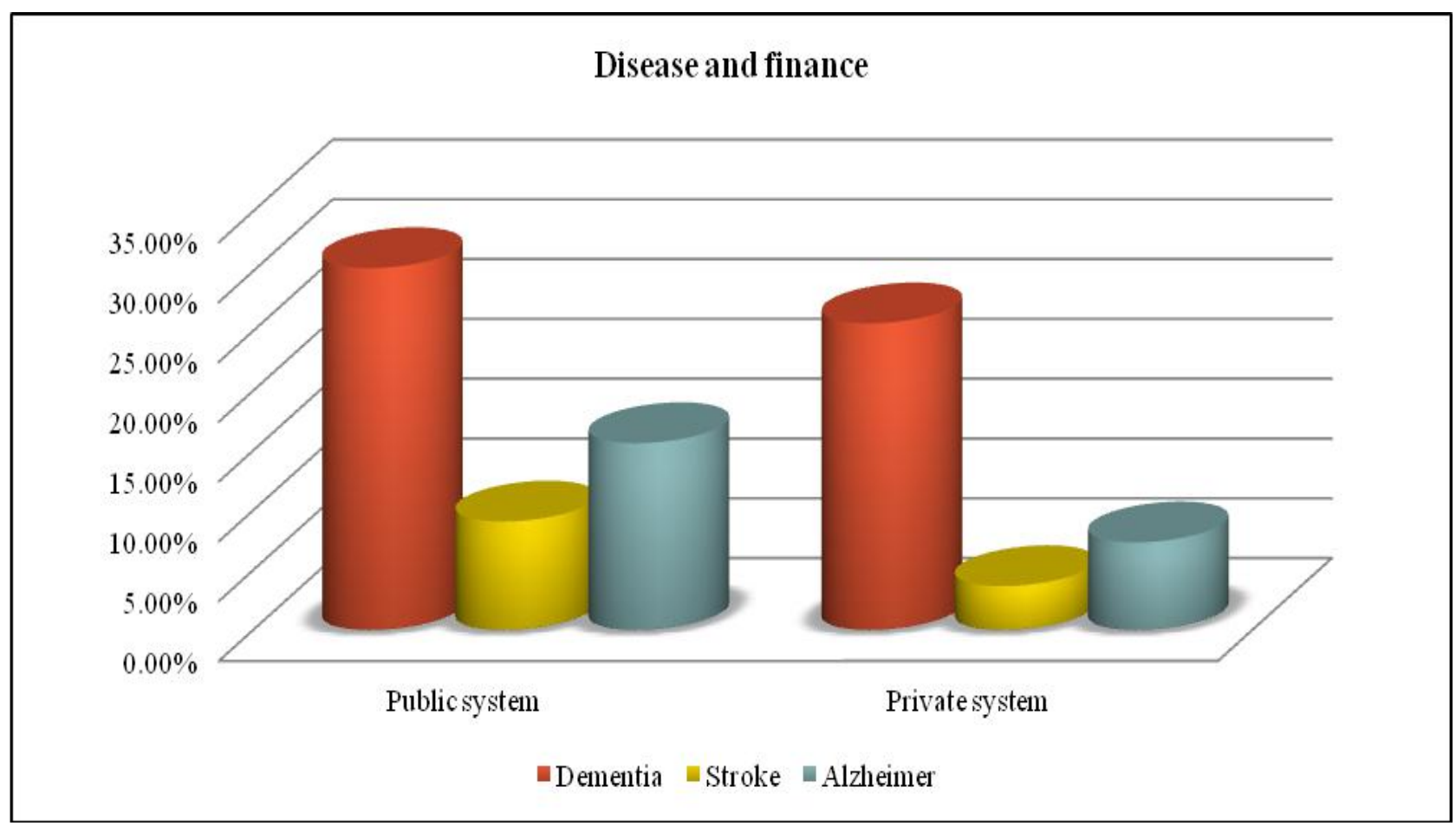

Fig. 2 Diseases and finance. 


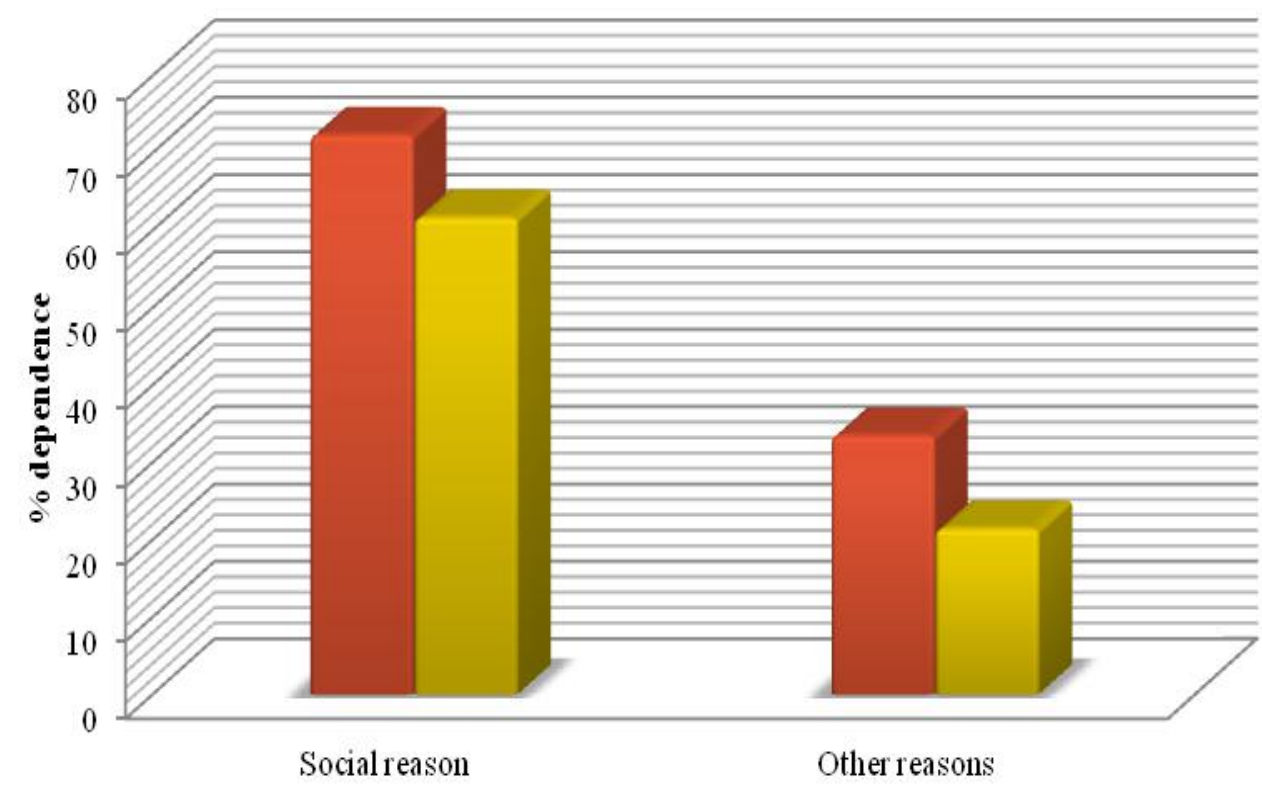

To the entrance

Nowadays

Reasons for admission

Fig. 3 Dependence and reason for admission over time.

\section{Discussion}

The goal of this study is to know the profile of institutionalized patients in geriatric residencies in our environment.

The percentage of women surpasses men, being the profile of the resident usually studied an elderly woman $(63 \%)$, which corroborates the findings in the previously reviewed literature [5-7]. Incidentally, the mainmarital status is widowhood (51.21\% against a $14.6 \%$ married, $25.8 \%$ single and $8.3 \%$ divorced), especially among women (Table 1).

The existence of the social problematic which conditions the person to live in their residence is the fundamental motif of their ingress in geriatric residences $(48.75 \%$ against $26.5 \%$ of neuropsychiatry condition and $24.6 \%$ of physical dependency). Often, elderly people who have lost their partners and have no descendants or people to look after them are sent by distant relatives to geriatric centers (public, for the most part). This widow, lacking children condition is present in greater numbers as well in our studied population, although it is true that other studies would be needed to determine if those are "risk factors" for their checking into nursing homes.

Males check into retirement homes beforehand, considering them more independent than females before admission. The fact that women join later could be attributed to the cultural existence of different roles for both, what give females a greater degree of autonomy. On the other hand, women longevity and the later admission have a greater morbidity rate in relation to males [8] being, therefore, the average Barthel index higher in males (Table 2).

In the year 2012, out of every nursing home in Spain, more than a quarter had private financings [9]. This bring light to the fact that even though the entrance of the private initiative and the creation of a business area dedicated to the elderly, it comes with almost a two-decade difference between Spain (90's) and European countries which assign more resources to this activity (France and Germany, in the 70's), this area has developed in the latest years with an increasing growth in our country [10]. In our case, more than $50 \%$ of the residents studied have a 
c o m p l e t e o r p a r t i a l w a y

Table 1 Resident profile.

\begin{tabular}{|c|c|c|c|}
\hline \multirow[t]{4}{*}{ Resident profile } & 82 years olc & & \\
\hline & \multicolumn{3}{|c|}{4 years institutionalized } \\
\hline & \multicolumn{3}{|l|}{ Widowed } \\
\hline & \multicolumn{3}{|c|}{ Admission due to social problems } \\
\hline & & Men & Women \\
\hline \multicolumn{2}{|c|}{ Admission age (years) } & 75.3 & 79.8 \\
\hline \multicolumn{2}{|l|}{ Current age (years) } & 79.4 & 83.6 \\
\hline \multicolumn{2}{|c|}{ Severe total dependence on income (\%) } & 33.6 & 55.7 \\
\hline \multicolumn{2}{|c|}{ Current severe total dependence $(\%)$} & 42.2 & 68.8 \\
\hline \multicolumn{2}{|c|}{ Civil status } & Widowed & Widowed \\
\hline \multicolumn{2}{|l|}{ Alzheimer (\%) } & 15.6 & 27.2 \\
\hline \multicolumn{2}{|l|}{ Incontinence $(\%)$} & 57.3 & 81.7 \\
\hline
\end{tabular}

of private financing, being age and independence level greater in these patients.

In the same way, more than $50 \%$ of patients present some kind of cognitive deterioration as could be expected from the revised literature [11], being this percentage greater if only the female group is taken into account (more than 60\%) [12]. Out of which, a $42 \%$ corresponds to Alzheimer's disease (22.93\% of the patients).

Finally, taking into consideration the difference on institutionalized patients' profiles according to rural or urban environments on which the nursing home is placed, patients in a rural environment are admitted beforehand and their average age is also significantly lower $76.15+0.81$ against $79.18+0$. Separating the reason of admission, the more frequent in rural environments is the neuropsychiatric pathology and in an urban environment the social problematic. Lastly, the level of dependency is greater in a rural environment, as well as the prevalence of dementia.

\section{Conclusions}

Comparing our area with previous literature, we notice the admission age in nursing homes is increasing over time. This could be related to the increase of the quality of life and the life expectancy.

There are circumstances that occur in greater numbers in the population studied (widow, female, children equal or less than 1 , etc.), but they need other studies to determine if they constitute a risk factor or not to enter in a nursing home. That would allow us to identify this population and perhaps intensify attention to them. This could be the next step to this research group.

The problematic social existence that conditions people to live in their home is the main reason for 
admission to a nursing home, highly above neuropsychiatric pathology and a situation of physical dependence.

Gender differences are not only due to those properly attributable differences in health but to the cultural existence of different roles, which provide a greater or lesser degree of autonomy.

\section{References}

[1] Sepúlveda, C., and Rivas, E. 2010 "Socio-Family Profile in Institutionalized Older Adults." Ciencia y. enfermería. 16 (3): 49-61.

[2] Hervás, A., and Arizcuren, M. A. 2004. "Influencia de Variables Sociosanitarias en la situación del estado cognitivo y de ánimo de los pacientes geriátricos en un centro de salud." Anales del Sistema Sanitario de Navarra, 211-23.

[3] Roosmalen, G., and Marcoen, A. 2006. "Personal Control of Care Provision and Functional Performance of Non-Institutionalized and Institutionalized Elderly." Gerontología y Geriatría, 37: 169-83.

[4] Ramos, C. P., and Larios, G. O. 2008. "Prevención y promoción de la salud en el anciano institucionalizado". Instituto de Salud Pública .Madrid Nueva Imprenta S.A

[5] Pinheiro, N. C. and Holanda, V. C. 2016. "Inequality in the Characteristics of the Institutionalized Elderly in the City of Natal, Brazil." Ciencia y Salud Coletiva 21 (11): 3399-405.

[6] Abellán García, A. 2013. El paisaje humano de las residencias es femenino y muy envejecido. Blog
Envejecimiento del CSIC (online). Available at : https://envejecimientoenred.wordpress.com.

[7] Frutos, E. and Bernal, J. C. 2013. "Perfil del anciano institucionalizado en residencias privadas de la comarca del Abadengo en Salamanca." Revista Española de Geriatría y Gerontología 48 (4): 203-4.

[8] De la Fuente, M. M. and Sanz, M. 2012. "Perfil del anciano institucionalizado en residencies privadas de la ciudad de Soria." Fisioterapia 34: 239-44.

[9] João Forjaz, M., and Rodríguez-Blázquez, C. 2015. Salud, calidad de vida y demencia: un estudio multidisciplinar. Blog Envejecimiento del CSIC (online) ISSN 2387-1512. Avaliable at: http://bit.ly/1JbsJ9z.

[10] Fernández, J. J. 2009. "Determinantes de la calidad de vida percibida por los ancianos de una residencia de tercera edad en dos contextos socioculturales diferentes, España y Cuba." Ph.D. thesis. Universidad de Valencia.

[11] Roca-Socarras, A., Henriette, K., Ramírez-Rojas, A., and Prosper, C. 2013. Rasgos distintivos de la comorbilidad y funcionalidad en ancianos institucionalizados con deterioro cognitivo y demencia. Revista Finlay [revista en Internet]. 2013 [citado 2017 Mar 2]; 3(3):[aprox. 10 p.]. Avaliable http://www.revfinlay.sld.cu/index.php/finlay/article/view/ 192. Accesed on $02 / 03 / 17$

[12] Blanco, J. A. 2004. "La demencia y el deterioro cognoscitivo en el anciano institucionalizado en la provincia de Zamora: estudio médico-psicológico y clínico-epidemiológico acerca de la prevalencia y factores relacionados, y validación del mini-examen cognoscitivo (MEC)." Ph.D. thesis, Universidad de Valladolid. 